\title{
Evaluation of Direct Acting Antivirals Efficiency in Turkish Patients with Chronic Hepatitis C Under Strict Rules
}

\author{
Figen Sarıgul ${ }^{1,{ }^{*}}$, Murat Sayan ${ }^{2,3}$, Ulku User $^{1}$ and Nefise Oztoprak ${ }^{1}$ \\ ${ }^{1}$ Infectious Disease and Clinical Microbiology, Antalya Education and Research Hospital, Health Sciences University, Antalya, Turkey \\ ${ }^{2}$ PCR Unit, Clinical Laboratory, Faculty of Medicine, Kocaeli University, Kocaeli, Turkey \\ ${ }^{3}$ Research Center of Experimental Health Sciences, Near East University, Nicosia, Northern Cyprus \\ "Corresponding author: Infectious Disease and Clinical Microbiology, Antalya Education and Research Hospital, Health Sciences University, Antalya, Turkey. Email: \\ drfigensarigul@yahoo.com.tr
}

Received 2017 October 02; Revised 2018 December 14; Accepted 2019 February 08.

\begin{abstract}
In chronic hepatitis C treatment, direct acting antivirals have a strong effect and are well tolerated since 2014, yet it is unclear whether resource-constrained countries have the same achievement. This study aimed at evaluating direct acting antivirals used to treat Turkish chronic hepatitis C patients between the years of 2016 to 2017. Within the one-year period, 101 out of 105 patients reached a sustained virological response rate. The type of direct acting antivirals and treatment length were chosen according to the Health Implementation Guideline of Turkey. The analyses of effectiveness according to therapeutic regimes showed the following sustained virological response rate: Ledipasvir/sofosbuvir and +/-; ribavirin (97\%), ombitasvir/paritepravir/dasabuvir and +/-; ribavirin (100\%) and sofosbuvir + ribavirin (100\%). One patient had virological relapse on the 12th week by the end of the therapy. In this patient, cross-resistance mutation Y93H was specified for the NS5A region. On the other hand, amino acid changes, S282G and C316S, were determined in the NS5B region. The adverse effects were $22 \%$ in all patients. Most of them were mild or moderate. The researchers concluded that the results of the highly efficient and well-tolerated therapy with direct acting antivirals could be examples in resource-constrained countries. In addition, resistant variants should be detected after unsuccessful treatment in the management of new therapy options.
\end{abstract}

Keywords: C Virus, Sofosbuvir, Ledipasvir, Ombitasvir, Drug Resistance

\section{Background}

Chronic hepatitis $\mathrm{C}(\mathrm{CHC})$ remains an important reason for liver disease due to the complication of cirrhosis, decompensated cirrhosis, hepatocellular carcinoma, and liver transplantation. The treatment of hepatitis $C$ virus (HCV) infection can effectively prevent the progression of the liver disease and decrease the risk of all-causes, such as extra hepatic manifestations and liver-related mortality and high economic cost on the patients (1-3).

The main goal of treatment of $\mathrm{CHC}$ is to achieve a sustained virological response rate (SVR), defined as a persistent absence of detectable HCV RNA by a sensitive assay at least 12 weeks and/or 24 weeks after the end of treatment (EOT) (4, 5). Until the early 1990s, there was no treatment available for HCV. Historically, the interferonbased treatment of HCV infection is associated with low efficacy and substantial side effects. Although the introduction of first-generation protease inhibitors (PIs; bocepre- vir and telaprevir) improved therapeutic outcomes in patients with HCV genotype (GT)1, the regimen was ineffective in individuals infected with other HCV GTs, prior nullresponders to interferon-based therapies, and in those with liver cirrhosis (6).

Development of second-generation direct acting antivirals (DAAs) is both well-tolerated and highly effective (7, 8 ). This was the revaluation to cure patients infected with HCV. Elimination of HCV infection seems possible in the near future, and is the target of the World Health Organization strategy on viral hepatitis (9). After 2013, the second generation of DAAs, including sofosbuvir (SOF) NS5B polymerase, the combination of SOF and the NS5A inhibitor ledipasvir (LDV/SOF and the combination of NS5A inhibitor ombitasvir (OBV), the NS3/4A inhibitor paritepravir (PTV) boosted with ritonavir (r), and the NS5B polymerase inhibitor dasabuvir (DSV), (OBV + PTV + r + DSV = 3D) with or without ribavirin (RBV) were approved respectively by Food and Drug Administration for the therapy of not only 
treatment-naive yet also treatment experienced patients infected with HCV with high SVR rates of $90 \%$ to $100 \%$ (1015). On the other hand, SOF, LDV/SOF, and 3D were approved during January, 2014, November, 2014, and February, 2015 by the European Medicines Agency, respectively (16).

The mean population of Turkey is 80 million and the seroprevalence of HCV infection in this population is about $0.9 \%(17,18)$. High risk populations, intravenous (IV) drug injection, alcohol abuse or multiple sexual intercourse in patients with HCV infection rate is higher (19). The risk factors were identified mainly as surgery and blood transfusion and in Turkish population HCV GT1b is dominated (84\%) which is important for the treatment regime selection (20-22). Unfortunately, accessibility to diagnosis and treatment rates of HCV infection are limited, and according to an international mathematical model, the probable diagnosis rate is $16 \%$ and the probable treatment rate is $0.8 \%$ for HCV infection in Turkey (23). Only three regimes of SOF + RBV, LDV/SOF, and 3D could have received approval during June, 2016 by Turkish Drug Administration for treatment of patients with $\mathrm{CHC}(24)$.

Unfortunately, in Turkey, all patients with CHC are neither eligible for treatment nor all kinds of DAAs, regardless of the clinical stage of liver impairment, and similar to most other countries around the world, tests and follow-ups cost high and jeopardize health budgets. For this reason, the treatment of $\mathrm{CHC}$ must be managed by Health Implementation Guideline of Turkey, prepared by the Ministry of Health (Table 1). These drugs have only been prescribed by infectious diseases and gastroenterologist physicians experienced in the treatment of HCV infection and they have been distributed at third level health hospital pharmacies that belong and are supervised by the Ministry of Health. On the other hand, if the treatment regime is out of recommendation of Turkish guidelines, a confirmation must be taken from the Ministry of Health (24). Overall, the most important parameter is that the patient with HCV infection has to be treated once only with DAAs in his life. Provided there is relapse after the therapy or breakthrough on the treatment, there may be no chance of being treated again.

\section{Objectives}

This article focused on how it goes on and what the treatment of HCV in Turkey after DAAs is? Under the Health Implementation Guideline of Turkey, the response rates and adverse effects of the treatment of HCV were evaluated.

\section{Methods}

\subsection{Patients}

Retrospectively, 105 patients were screened in the current evaluation yet only 101 had completed treatment and included in efficacy and safety analysis between June 2016 and June 2017 at the Infectious Diseases and Clinical Microbiology Department of Antalya Education and Research Hospital at Health Sciences University of Turkey (Figure 1). Patients included in this evaluation were over 18 years of age with HCV RNA positive test results for at least six months prior to screening. Co-infected patients with human immunodeficiency virus were not included. According to the Health Implementation Guideline of Turkey, DAAs are chosen for GT and previous treatment experienced and the treatment length varied from 12 to 24 weeks. For the study period, Turkish treatment guidelines designate $3 \mathrm{D}$ as the preferred regimen in GT1 and 4 in fibrosis stage F1 - 3 infected patients after March 2017, except for the patients, who were Child-Pugh B or C (in whom LDV/SOF \pm RBV were preferred for 12 to 24 weeks and the patients previously treated with first generation protease inhibitors). Before March 2017, the patients, whose liver fibrosis stage were $\geq$ F3 could be treated with DAAs. Written informed consent was provided by the patients. The study was done according to the Declaration of Helsinki.

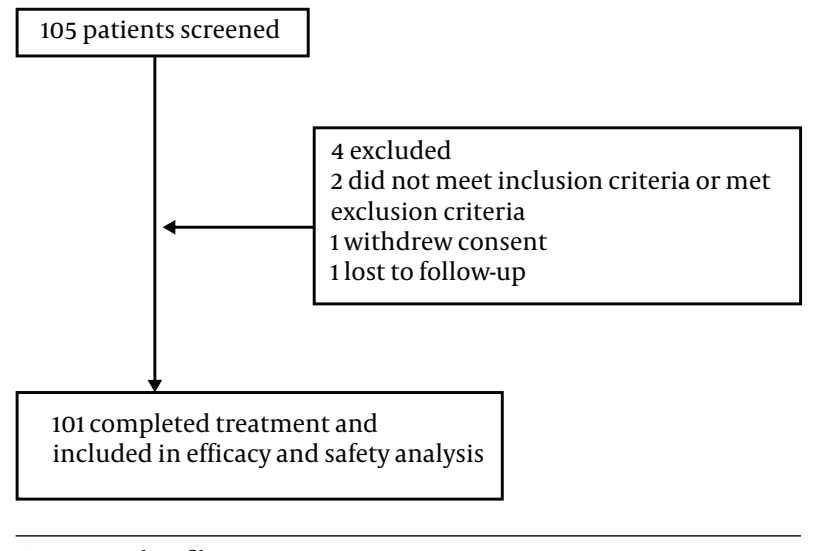

Figure 1. Trial profile

\subsection{Therapeutic Evaluation}

In Turkey, it is compulsory for all treatment-naive patients to have $\geq$ F1 liver biopsy score (by Ishak) to be treated with DAAs (25). However, if patients are treatmentexperienced with pegylated interferon + RBV or primer generation PIs, they can be candidates for DAAs treatment 


\begin{tabular}{|c|c|c|c|c|c|c|}
\hline \multirow{2}{*}{$\begin{array}{l}\text { HCV } \\
\text { Geno- } \\
\text { type }\end{array}$} & \multicolumn{2}{|c|}{ Non-Cirrhosis (F1-3) } & \multicolumn{2}{|c|}{ Compansated Cirrhosis (F4 - 6) (Child-Pugh A) } & \multicolumn{2}{|c|}{ Decompansated Cirrhosis (F4 - 6) (Child-Pugh B, C) } \\
\hline & Naive & Experienced & Naive & Experienced & Naive & Experienced \\
\hline \multirow{3}{*}{$\mathbf{1 a}$} & \multirow{3}{*}{$3 \mathrm{D}+\mathrm{RBV}-12 \mathrm{wk}$} & $\begin{array}{l}\text { LDV/SOF + } \\
\text { RBV-12 wk }\end{array}$ & \multirow{3}{*}{$3 \mathrm{D}+\mathrm{RBV}-24 \mathrm{wk}$} & LDV/SOF + RBV-12 wk & $\mathrm{LDV} / \mathrm{SOF}+\mathrm{RBV}-12 \mathrm{wk}$ & LDV/SOF + RBV-12 wk \\
\hline & & LDV/SOF-24 wk & & LDV/SOF-24 wk & \multirow{2}{*}{ LDV/SOF-24 wk } & \multirow{2}{*}{ LDV/SOF-24 wk } \\
\hline & & $3 \mathrm{D}+\mathrm{RBV}-12 \mathrm{wk}^{\mathrm{a}}$ & & $3 \mathrm{D}+\mathrm{RBV}-24 \mathrm{wk}^{\mathrm{a}}$ & & \\
\hline \multirow{3}{*}{$\mathbf{1 b}$} & \multirow{3}{*}{$3 \mathrm{D}-12 \mathrm{wk}$} & $\begin{array}{l}\text { LDV/SOF + } \\
\text { RBV-12 wk }\end{array}$ & \multirow{3}{*}{ 3D-12 wk } & $\mathrm{LDV} / \mathrm{SOF}+\mathrm{RBV}-12 \mathrm{wk}$ & $\mathrm{LDV} / \mathrm{SOF}+\mathrm{RBV}-12 \mathrm{wk}$ & $\mathrm{LDV} / \mathrm{SOF}+\mathrm{RBV}-12 \mathrm{wk}$ \\
\hline & & LDV/SOF-24 wk & & LDV/SOF-24 wk & \multirow{2}{*}{ LDV/SOF-24 wk } & \multirow{2}{*}{ LDV/SOF-24 wk } \\
\hline & & $3 \mathrm{D}-12 \mathrm{wk}^{\mathrm{a}}$ & & $3 \mathrm{D}-12 \mathrm{wk}^{\mathrm{a}}$ & & \\
\hline 2 & $\mathrm{SOF}+\mathrm{RBV}-12 \mathrm{wk}$ & $\mathrm{SOF}+\mathrm{RBV}-12 \mathrm{wk}$ & $\mathrm{SOF}+\mathrm{RBV}-12 \mathrm{wk}$ & $\mathrm{SOF}+\mathrm{RBV}-12 \mathrm{wk}$ & $\mathrm{SOF}+\mathrm{RBV}-12 \mathrm{wk}$ & $\mathrm{SOF}+\mathrm{RBV}-12 \mathrm{wk}$ \\
\hline \multirow{2}{*}{3} & \multirow{2}{*}{$\mathrm{SOF}+\mathrm{RBV}-24 \mathrm{wk}$} & \multirow{2}{*}{$\mathrm{SOF}+\mathrm{RBV}-24 \mathrm{wk}$} & SOF + RBV-24 wkLDV/SOF- & $\mathrm{SOF}+\mathrm{RBV}-24 \mathrm{wk}$ & \multirow{2}{*}{$\mathrm{SOF}+\mathrm{RBV}-24 \mathrm{wk}$} & $\mathrm{SOF}+\mathrm{RBV}-24 \mathrm{wk}$ \\
\hline & & & $24 \mathrm{wk}$ & LDV/SOF-24 wk & & LDV/SOF-24 wk \\
\hline \multirow{3}{*}{4} & \multirow{3}{*}{$\begin{array}{c}\mathrm{OBV}+\mathrm{PTV}+ \\
\mathrm{RBV}-12 \mathrm{wk}\end{array}$} & $\begin{array}{l}\text { LDV/SOF + } \\
\text { RBV-12 wk }\end{array}$ & \multirow{3}{*}{$\mathrm{OBV}+\mathrm{PTV}+\mathrm{RBV}-12 \mathrm{wk}$} & LDV/SOF + RBV-12 wk & $\mathrm{LDV} / \mathrm{SOF}+\mathrm{RBV}-12 \mathrm{wk}$ & $\mathrm{LDV} / \mathrm{SOF}+\mathrm{RBV}-12 \mathrm{wk}$ \\
\hline & & LDV/SOF-24 wk & & LDV/SOF-24 wk & \multirow{2}{*}{ LDV/SOF-24 wk } & \multirow{2}{*}{ LDV/SOF-24 wk } \\
\hline & & $\begin{array}{l}\mathrm{OBV}+\mathrm{PTV}+ \\
\mathrm{RBV}-12 \mathrm{wk}^{\mathrm{a}}\end{array}$ & & $\mathrm{OBV}+\mathrm{PTV}+\mathrm{RBV}-12 \mathrm{wk}^{\mathrm{a}}$ & & \\
\hline
\end{tabular}

${ }^{\mathrm{a}}$ Except for previously treated with protease inhibitors, and patients with Child-Pugh B or C cirrhosis.

without liver biopsy. Before DAAs therapy, patients are expected to undergo pretreatment evaluation to identify the GT of HCV as much as a certain physical examination, some biochemical-hematological tests, and surely ultrasonography.

These factors directly influence the choice and duration of therapy. The DAAs included combination of $90 \mathrm{mg}$ LDV/400 mg SOF daily, 3D (OBV 25 mg, PTV 150 mg, r 100 $\mathrm{mg}$ daily, and DSV $250 \mathrm{mg}$ twice daily) with or without RBV (1000/1200 mg daily) and $400 \mathrm{mg} / 1000 \mathrm{mg}$ SOF $+1200 \mathrm{mg}$ RBV daily. Another consideration before starting therapy should be of patients' co-morbidities and their medication list that can interact with DAAs. Their medications were checked in the Liverpool drug-drug interaction (DDI) (www.hep-druginteractions.org) online.

\subsection{HCV RNA Analysis}

The HCV extraction with magnetic particle technology and RNA measurement were performed using commercial PCR analysis - Abbott M2000 SP / Abbott RealTime HCV Amplification Kit with a lower bound of $10 \mathrm{IU} / \mathrm{mL}$ (Abbott Molecular Inc., Des Plaines, IL, USA).

\subsection{Hepatitis C Virus Genotyping/Subtyping}

The HCV genotype kit by Abbott (Abbott Molecular Inc., IL, USA) is used for HCV genotyping/subtyping in CHC pa- tients. The HCV strain was genotyped according to a real time-polymerase chain reaction (RT-PCR) assay.

Abbott RealTime HCV genotype II assay is the use of genotypes, 1, 2, 3, 4, 5 perceptions and 6, and genotypespecific fluorescently labeled oligonucleotide probes 1a and $1 \mathrm{~b}$ subtype.

\subsection{Drug Resistance Mutation Analysis}

Genotypic resistance analysis was demonstrated by Sanger dideoxy sequencing of the NS3 region (amino acid position from 985 to 1295), NS5A (amino acid position from 1935 to 2237), and the NS5B regions (amino acid position from 2644 to 3054). An appropriate method of HCV drug resistance mutations in-house sequencing kit (Bosphore $\mathrm{V}$ 1.0 - GENEWORKS Anatolia, Istanbul - Turkey).

The HCV strain AF483269.1 was used for the primary pairs. Thermal protocols for RT-PCR and Sanger dideoxy sequencing were applied, according to the manufacturer's instructions. For PCR purification using high pure purification kit (Roche Diagnostics, Mannheim, Germany) and sequenced directly with the ABI PRISM 310 Genetic analyzer using Cycle Sequencing Kit (Applied Biosystems, CA, USA). The arrays obtained by electrophotogram (InforMax, Invitrogen, Frederick, MD) were combined using Vector NTI V.5.1.

The geno2pheno drug resistance tool (http://coreceptor.bioinf.mpi-inf.mpg.de/) defined the 
DAA suscebtibility. HCV is a database designed for rapid computer assisted phenotyping of virtual phenotypes and is a database that accepts sequences of genomics (such as FASTA form nucleic acid) intermediate-known mutation and input sequences for approaching drugs. HCV D90208 and HQ850279 were used as reference strains for HCV NS3, NS5A, and NS5B regions, respectively.

The sequence of HCV; NS3 inhibitors; faldaprevir, boseprevir, pariteprevir, grazoprevir, simeprevir, telaprevir, asunaprevir, NS5A inhibitors; elbasvir, velpatasvir daclatasvir, ombitasvir, ledipasvir, and NS5B inhibitors; sofosbuvir and dasabuvir analyzed.

\subsection{Statistical Analysis}

A descriptive analysis was conducted by calculating frequencies and percentages for qualitative variables and means with standard deviation or median with interquartile range for quantitative variables. All analyses were conducted with Microsoft Excel 2017. The two-tailed $t$ test was conducted to compare the means of the HCV RNA quantification rates at four weeks; between the naive patients and treatment experienced with pegylated-interferon + RBV patients.

\section{Results}

Baseline patients' characteristics and demographics are presented in Table 2. The majority of patients (58\%) were naive, the median HCV RNA load was 2.75 + E6 IU/mL, and GT1b was the most predominant among them (59\%), most of whom were noncirrhotic. Concerning hepatic fibrosis stage, $87 \%$ (61 out of 70 ) of patients were F1 - 3. Only 13\% (9 out of 70) of patients had a high fibrosis stage (F4 $6)$. In total, 31 patients did not have liver biopsy scores.

Twenty-nine patients received LDV/SOF alone and 10 received RBV as well; 33 patients received 3D alone and 19 with RBV; and 10 patients received SOF + RBV. Less than half of the patients (39\%) received $\mathrm{RBV}$ and its use increased in cirrhotic and treatment experienced patients. The duration of treatment was 12 weeks in 86 patients and 24 weeks in 15 patients, six of whom were treatment experiencedcirrhotic patients treated with LDV/SOF, one was naivenoncirrhotic patient treated with LDV/SOF, and eight patients were GT3 treated with SOF + RBV.

The most common co-morbidities were hypertension (20\%), former intravenous drug use, clean for the last six months and not requiring opioid replacement therapy currently (16\%), diabetes mellitus (10\%), hypotiroidism
(9\%), end stage renal disease (6\%), and depression (5\%). Only two patients had co-infection with hepatitis $\mathrm{B}$ and eight patients had isolated anti-HBc IgG (HBV DNA negative). Almost $50 \%$ of patients were on concomitant drugs.

Efficacy outcomes and viral responses with treatment regimes are shown in Table 3, which shows treatment regimes, duration of therapy by GTs, and previous treatment status. The analyses of effectiveness, according to therapeutic regimes, showed the following SVR: LDV/SOF \pm RBV (97\%), 3D \pm RBV (100\%) and SOF + RBV (100\%).

All 101 patients completed their treatment period without any interruption except for one patient, who was unable to pay for LDV/SOF pills for five days due to insurance matters. However, SVR12 had been reached due to the five-day discontinuation on the fourth week of the treatment, quantification of HCV RNA below the undetectable limit was higher in treatment naive patients (84\%) than in the treated patients $(53 \%)(\mathrm{P}<0.001)$. At the EOT, all patients had undetectable HCV RNA (100\%). However, in 100 out of 101 patients who achieved SVR, an overall effectiveness of $99 \%$ was found. One patient, who did not achieve SVR, had virological failure (VF) with undetectable viral load by the fourth week of treatment until completion, yet a virological relapse on the 12th week after the end of the therapy. In this patient, cross-resistance mutation Y93H was specified for the NS5A region. On the other hand, amino acid changes, S282G and C316S, were determined in the NS5B region The characteristics of the 58-year-old patient were GT1b, baseline HCV RNA 4.2 + E6 IU/mL, fibrosis stage F5, Child-Pugh B, compensated cirrhosis, pegylatedinterferon + RBV experienced, null response, and treatment with LDV/SOF + RBV for 12 weeks.

Laboratory parameters with DAAs are shown in Table 4. Aminotransaminases were normalized by week four and kept on at the EOT and 12 weeks after the end of treatment. The other parameter mean values were normal from the beginning of the treatment to week 12 after the end of therapy.

Patients with adverse effects (AEs) and laboratory abnormalities are presented in Table 5. The total AEs were $22 \%$ in all patients, though no patient discontinued the treatment due to AEs. Most of AEs were mild or moderate and only one patient, treated with $3 \mathrm{D}+\mathrm{RBV}$ experienced a severe syncope with accompanying hallucination, which was resolved on shut down of RBV. The most common form of AEs was fatigue in 11 (11\%) patients, especially within 15 days after the treatment was started with 3D + RBV. Most of the AEs were observed in patients treated with SOF + 


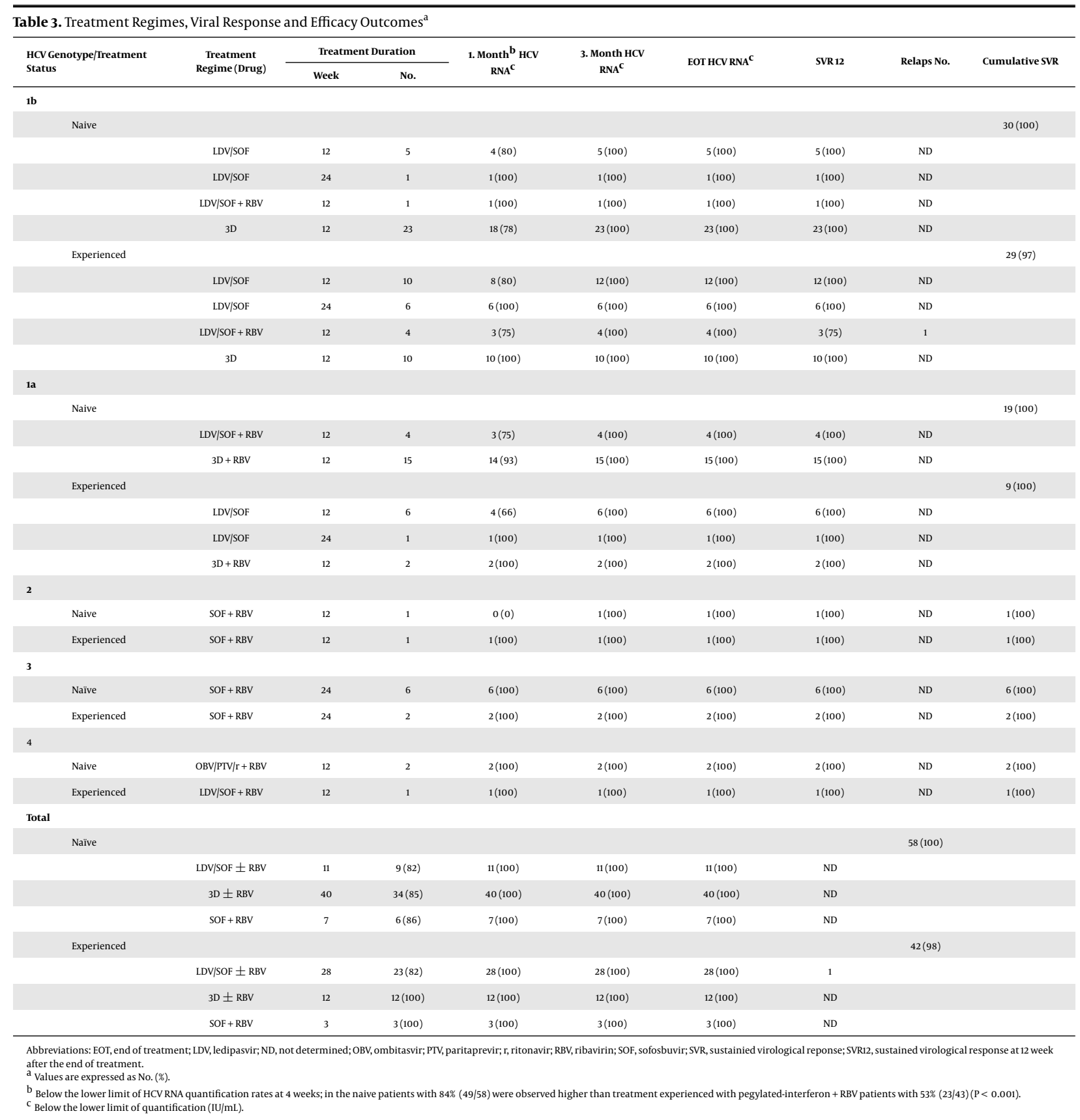

RBV (60\%). This was followed by 3D + RBV (32\%), 3D (21\%), $\mathrm{LDV} / \mathrm{SOF}+\mathrm{RBV}(10 \%)$, and LDV/SOF (7\%). As for the laboratory abnormalities, bilirubin elevations were observed only in two patients treated with 3D + RBV and the decrease of hemoglobin were observed in two patients treated with 3D + RBV on the 10th week of treatment, and RBV doses were reduced to $800 \mathrm{mg}$ for the last two weeks.

\section{Discussion}

This evaluation was performed at a single centre on the viral response of the patients infected by GT 1, 2, 3, and $4 \mathrm{CHC}$ patients, who were treated with three different $\mathrm{DAA}(\mathrm{LDV} / \mathrm{SOF}$, 3D and SOF $+\mathrm{RBV}$ ) regimes, according to the Health Implementation Guideline of Turkey. The results suggested SVR rates of $100 \%$ in naive and $98 \%$ in treatment experienced patients, close to that reported in clinical tri- 


\begin{tabular}{|c|c|c|c|c|}
\hline Laboratory Value & Baseline (Mean) & Treatment Week 4 (Mean) & End of Therapy (Mean) & Post 12 (Mean) \\
\hline ALT, U/L & $146(8-549)$ & $20(6-88)$ & $22(7-110)$ & $22(8-100)$ \\
\hline AST, $\mathbf{U} / \mathbf{L}$ & $56(12-260)$ & $24(7-100)$ & $24(10-88)$ & $26(7-68)$ \\
\hline T.Bilirubin, mg/dL & $1.1(0.4-3)$ & $0.99(0.68-3.5)$ & $1.1(0.54-3.0)$ & $1.1(0.45-3.1)$ \\
\hline D.Bilirubin, mg/dL & $0.12(0.08-1.5)$ & $0.14(0.08-0.20)$ & $0.11(0.07-0.22)$ & $0.10(0.08-0.24)$ \\
\hline Platelet count $\times \mathbf{1 0}^{9}$ & $207(65-570)$ & $221(85-660)$ & $221(80-550)$ & $220(80-550)$ \\
\hline Hemoglobin, g/dL & $13.1(8-17)$ & $13(9-16)$ & $12.9(9-15)$ & $13(9-15)$ \\
\hline Albumin, $\mathbf{g} / \mathbf{d L}$ & $4.2(2.5-4.5)$ & $4(3.8-5.3)$ & $4.1(3.7-5.1)$ & $4.2(2.6-4.1)$ \\
\hline
\end{tabular}

${ }^{a}$ Values are expressed as median (range).

Table 5. Patients with Advers Effects (AEs) and Laboratory Abnormalities ${ }^{\mathrm{a}}$

\begin{tabular}{|c|c|c|c|c|c|c|}
\hline \multirow{2}{*}{ Event } & \multicolumn{5}{|c|}{ Treatment Regime } & \multirow{2}{*}{ Total $(\mathbf{n}=101)$} \\
\hline & $3 \mathbf{D}(\mathbf{n}=33)$ & $3 D+\operatorname{RBV}(n=19)$ & $\operatorname{LDV} / \operatorname{SOF}(\mathbf{n}=29)$ & $\operatorname{LDV} / \operatorname{SOF}+\operatorname{RBV}(n=10)$ & $\operatorname{SOF}+\operatorname{RBV}(n=10)$ & \\
\hline Severe AE & ND & ND & ND & 1 & ND & $1(0.99)$ \\
\hline AE to stop treatment & ND & ND & ND & ND & ND & ND \\
\hline \multicolumn{7}{|l|}{ Common AEs } \\
\hline Fatigue & 2 & 5 & 2 & ND & 2 & $11(11)$ \\
\hline Nausea/vomiting & ND & ND & ND & ND & 2 & $2(2)$ \\
\hline Diarrhea & ND & 1 & ND & ND & ND & $1(2)$ \\
\hline Headache & ND & ND & ND & ND & 1 & $1(1)$ \\
\hline Artharalgia & ND & - & ND & ND & 2 & $2(1)$ \\
\hline Myalgia & $\mathrm{ND}$ & 2 & ND & ND & & $2(1)$ \\
\hline Stomach ache & ND & ND & 1 & ND & 1 & $2(1)$ \\
\hline Dizziness & 1 & 2 & 2 & ND & 2 & $7(7)$ \\
\hline Insomnia & 2 & 4 & ND & ND & ND & $6(6)$ \\
\hline Pruritis & 1 & 2 & ND & ND & ND & $3(3)$ \\
\hline E. nodosum & ND & ND & ND & ND & 1 & $1(1)$ \\
\hline Hallucination & ND & ND & ND & 1 & ND & $1(1)$ \\
\hline $\begin{array}{l}\text { Hemoglobin }< \\
\text { 10g/dL }\end{array}$ & ND & 2 & ND & ND & ND & $2(2)$ \\
\hline $\begin{array}{l}\text { Total bilirubin }>1.5 \text { - } 3 \\
\text { XULN }\end{array}$ & ND & 2 & ND & ND & ND & $2(2)$ \\
\hline Total & $7(21)$ & $6(32)$ & $2(7)$ & $1(10)$ & $6(60)$ & $22(22)$ \\
\hline
\end{tabular}

Abbreviation: ND, not determined.

${ }^{a}$ Values are expressed as No. (\%).

als (26-28). On the other hand, the high SVR rates could be connected in that both the patient fibrosis stage of liver biopsy was $\mathrm{F} 1-3$ (87\%) and the majority of patients were naive (58\%). It is important to note that we can make any conclusion concerning the efficacy and safety of DAAs in patients with more severe liver disease.

Besides the limited choices and uses of DAAs in Turkish reimbursement system of DAAs, at the center of the cur- rent research, all three regimes were good in real world practice, achieving SVR rates, similar to other global clinical studies (29-31). Amongst treatment experienced and compensated cirrhosis patients, only one treated with LDV/SOF + RBV relapsed during the 12 weeks treatment duration. Turkish, European Association for the Study of the Liver and American Association for the study of Liver Diseases guidelines recommend that LDV/SOF plus weight- 
based RBV for 12 weeks for patients with HCV GT1b infection, who have compensated cirrhosis, in whom prior pegylated interferon-RBV treatment has failed, which is why in this patient, treatment failure was not expected $(4,24$, 32). The therapeutic failure, therefore, was assumed to be resistance-related.

Resistance-associated amino acid substitutions can be detected during the DAA treatment in CHC patients (33). The findings indicate that the NS5A resistance associated mutation (Y93H) could be effective in relapse in LDV/SOF therapy. The $\mathrm{Y} 93 \mathrm{H}$ is a mutation related to cross-resistance in the NS5A inhibitor group (34). However, Y93H mutation was the first case to be reported in Turkey $(35,36)$. These findings suggested the resistance analysis, as experienced in CHC patients on therapy should remain a basic part of the management. Preservation of plasma samples before treatment may be helpful in assessing the presence of previously resistant variants when there is relapse and/or breakthrough after/during treatment. In addition, DAA resistance analysis can facilitate the determination of new treatment options with DAAs in unsuccessful CHC therapies. Retreatment of such cases that have failed in the prior therapy has to be carried out by the Ministry of Health immediately, in which retreatment with DAAs is unfortunately not possible.

The comorbidities were common in the patients. HCV after intravenous drug use is very prevalent. The most important GT causing HCV infection in IDUs globally is GT1a, as is the case in the general population, yet GT3 is also highly prevalent in IDUs (37). In the patients, 12 of 16 IDUs were GT1a and four were GT3 whom SVR rates were $100 \%$ and the compliance of therapy was perfect. The IDUs are major contributors to the worldwide burden of the disease. Even though there are effective interventions to prevent and treat these important causes of health burden, the current researchers selected patients, who had not been injected in the clinic over the last six months and did not require opioid replacement therapy at this time because the costs of drugs, tests, and follow-ups were high (38). Since it was impossible to retreat, the researchers had to choose patients, who were thought that treatment compliance might be good and the patients, who might not be re-infected. Only six of the patients with end stage renal disease were treated with $3 \mathrm{D} \pm \mathrm{RBV}$ that the SVR rate was $100 \%$. In two HBsAg positive and eight isolated anti-HBc IgG positive patients, there was no reactivation, such as that of some studies $(39,40)$.

The drug drug interactions (DDIs) has emerged as an additional issue in clinical practice for the treatment of HCV because generally HCV infected patients are over 40 years old with clinically significant co- morbidities and associated accompanying medications. In Germany, a realworld study evaluated the significance of DDIs between HCV patients' treatment and new DAA regimens (41). The patients, who were treated with 3D, 66.3\% experienced significant DDIs; $8.4 \%$ of these DDIs occurred. In the current patients, 6\% (6/101) received 3D regiments recommended due to the DDIs. In the current evaluation concomitant drugs per patient were one to two drugs in $17 \%$, three to four drugs in $13 \%$, five to six drugs in $13 \%$ and $\geq$ six drugs in $8 \%$ of patients.

In conclusion, the treatments experience showed that DAAs were highly efficient and well-tolerated in Turkish patients with $\mathrm{CHC}$. The development of drug resistance may explain the relapse of plasma HCV RNA during the therapy. Therefore, drug resistance testing should remain a basic part of management in unsuccessful DAA treatments.

\section{Footnotes}

Authors' Contribution: Figen Sarigul chosed the study, designed, wrote and collected data. Murat Sayan worked the all laboratuary and edited the article. Ulku User helped to collect the data. Nefise Oztoprak was a supervisor.

Conflict of Interests: No competing financial interests exist.

Ethical Approval: This study was approved by the Clinical Research Ethics Committee of Health Sciences University Antalya Education and Research Hospital, Clinical Research Turkey (Decision no: 24/56 - 07.08.2017).

Funding/Support: None.

\section{References}

1. Lee MH, Yang HI, Lu SN, Jen CL, You SL, Wang LY, et al. Chronic hepatitis $C$ virus infection increases mortality from hepatic and extrahepatic diseases: A community-based long-term prospective study.JInfect Dis. 2012;206(4):469-77. doi: 10.1093/infdis/jis385. [PubMed: 22811301].

2. Bruno S, Stroffolini T, Colombo M, Bollani S, Benvegnu L, Mazzella $\mathrm{G}$, et al. Sustained virological response to interferon-alpha is associated with improved outcome in HCV-related cirrhosis: A retrospective study. Hepatology. 2007;45(3):579-87. doi: 10.1002/hep.21492. [PubMed: 17326216].

3. Zare F, Fattahi MR, Sepehrimanesh M, Safarpour AR. Economic burden of hepatitis $C$ virus infection in different stages of disease: A report from Southern Iran. Hepat Mon. 2016;16(4). e32654. doi: 10.5812/hepatmon.32654. [PubMed: 27257424]. [PubMed Central: PMC4887962]. 
4. European Association for the Study of the Liver. EASL 2017 clinical practice guidelines on the management of hepatitis $C$ virus infection. J Hepatol. 2017;66(1):153-94. doi:10.1016/j.jhep.2017.03.021.

5. Bruno S, Di Marco V, Iavarone M, Roffi L, Crosignani A, Calvaruso V, et al. Survival of patients with HCV cirrhosis and sustained virologic response is similar to the general population.J Hepatol. 2016;64(6):121723. doi:10.1016/j.jhep.2016.01.034. [PubMed: 27059129].

6. Jaroszewicz J, Flisiak-Jackiewicz M, Lebensztejn D, Flisiak R. Current drugs in early development for treating hepatitis $C$ virus-related hepatic fibrosis. Expert Opin Investig Drugs. 2015;24(9):1229-39. doi: 10.1517/13543784.2015.1057568. [PubMed: 26122697].

7. Fox DS, McGinnis JJ, Tonnu-Mihara IQ, McCombs JS. Comparative treatment effectiveness of direct acting antiviral regimens for hepatitis C: Data from the Veterans administration. J Gastroenterol Hepatol. 2017;32(6):1136-42. doi: 10.1111/jgh.13652. [PubMed: 27869323].

8. Terrault NA, Zeuzem S, Di Bisceglie AM, Lim JK, Pockros PJ, Frazier LM, et al. Effectiveness of ledipasvir-sofosbuvir combination in patients with hepatitis $C$ virus infection and factors associated with sustained virologic response. Gastroenterology. 2016;151(6):1131-1140 e5. doi: 10.1053/j.gastro.2016.08.004. [PubMed: 27565882]. [PubMed Central: PMC5300778].

9. World Health Organization. Global health sector strategy on viral hepatitis 2016-2021. Towards ending viral hepatitis. WHO Press through the WHO website; [cited 2018]. Available from: www.who.int/about/ licensing/copyright_form/en/index.html.

10. Rodriguez-Torres M, Lawitz E, Kowdley KV, Nelson DR, Dejesus E, McHutchison JG, et al. Sofosbuvir (GS-7977) plus peginterferon/ribavirin in treatment-naive patients with HCV genotype 1: A randomized, 28-day, dose-ranging trial. J Hepatol. 2013;58(4):6638. doi: 10.1016/j.jhep.2012.11.018. [PubMed: 23183528].

11. Link JO, Taylor JG, Xu L, Mitchell M, Guo H, Liu H, et al. Discovery of ledipasvir (GS-5885): A potent, once-daily oral NS5A inhibitor for the treatment of hepatitis C virus infection. J Med Chem. 2014;57(5):203346. doi: 10.1021/jm401499g. [PubMed: 24320933].

12. Krishnan P, Beyer J, Mistry N, Koev G, Reisch T, DeGoey D, et al. In vitro and in vivo antiviral activity and resistance profile of ombitasvir, an inhibitor of hepatitis C virus NS5A. Antimicrob Agents Chemother. 2015;59(2):979-87. doi: 10.1128/AAC.04226-14. [PubMed: 25451055]. [PubMed Central: PMC4335823].

13. Andreone P, Colombo MG, Enejosa JV, Koksal I, Ferenci P, Maieron A, et al. ABT-450, ritonavir, ombitasvir, and dasabuvir achieves $97 \%$ and $100 \%$ sustained virologic response with or without ribavirin in treatment-experienced patients with HCV genotype $1 \mathrm{~b}$ infection. Gastroenterology. 2014;147(2):359-365 e1. doi:10.1053/j.gastro.2014.04.045. [PubMed: 24818763].

14. Lawitz E, Makara M, Akarca US, Thuluvath PJ, Preotescu LL, Varunok $\mathrm{P}$, et al. Efficacy and safety of ombitasvir, paritaprevir, and ritonavir in an open-label study of patients with genotype $1 \mathrm{~b}$ chronic hepatitis $C$ virus infection with and without cirrhosis. Gastroenterology. 2015;149(4):971-80 e1. doi: 10.1053/j.gastro.2015.07.001. [PubMed: 26170136].

15. Hezode C, Asselah T, Reddy KR, Hassanein T, Berenguer M, FleischerStepniewska K, et al. Ombitasvir plus paritaprevir plus ritonavir with or without ribavirin in treatment-naive and treatment-experienced patients with genotype 4 chronic hepatitis $C$ virus infection (PEARLI): A randomised, open-label trial. Lancet. 2015;385(9986):2502-9. doi: 10.1016/S0140-6736(15)60159-3. [PubMed: 25837829].

16. EMA drug Safety Communication. EMA recommends avoidence of certain hepatitis C medicines and amiodarone together. 2018.

17. Turkish Statistical Institute. Data of Turkish Statistical Institute in 2017. 2017, [cited 30 Jan 2017]. Available from: http://www.turkstat.gov.tr.
18. Bruggmann P, Berg T, Ovrehus AL, Moreno C, Brandao Mello CE, Roudot-Thoraval F, et al. Historical epidemiology of hepatitis $C$ virus (HCV) in selected countries. J Viral Hepat. 2014;21 Suppl 1:5-33. doi: 10.1111/jvh.12247. [PubMed: 24713004].

19. Shamsdin SA, Sepehrimanesh M, Pezeshki B, Nejabat M. Seroprevalence of hepatitis B and C in patients with hemophilia: A single-centre descriptive study. Shiraz Med J. 2015;16(7). doi: 10.17795/semj24573.

20. Fattahi MR, Safarpour A, Sepehrimanesh M, Hosseini Asl SM, Mohamaddoust $F$. The prevalence of hepatitis $C$ virus infection and its related risk factors among the rural population of fars province, southern iran. Hepat Mon. 2015;15(2). e24734. doi: 10.5812/hepatmon.24734. [PubMed: 25788957]. [PubMed Central: PMC4350250].

21. Karaca C, Cakaloglu Y, Demir K, Ozdil S, Kaymakoglu S, Badur S, et al. Risk factors for the transmission of hepatitis $C$ virus infection in the Turkish population. Dig Dis Sci. 2006;51(2):365-9. doi: 10.1007/s10620006-3139-6. [PubMed:16534682].

22. Kabakci Alagoz G, Karatayli SC, Karatayli E, Celik E, Keskin O, Dinc $B$, et al. Hepatitis $C$ virus genotype distribution in Turkey remains unchanged after a decade: Performance of phylogenetic analysis of the NS5B, E1, and 5'UTR regions in genotyping efficiency. Turk J Gastroenterol. 2014;25(4):405-10. doi: 10.5152/tjg.2014.7083. [PubMed: 25254523].

23. Dore GJ, Ward J, Thursz M. Hepatitis C disease burden and strategies to manage the burden (Guest Editors Mark Thursz, Gregory Dore and John Ward). J Viral Hepat. 2014;21 Suppl 1:1-4. doi: 10.1111/jvh.12253. [PubMed: 24713003].

24. Health Ministry of Turkey. Health implementation guideline. [cited 25 Mar 2017]. Available from: http://www.sgk.gov.tr.

25. Ishak K, Baptista A, Bianchi L, Callea F, De Groote J, Gudat F, et al. Histological grading and staging of chronic hepatitis. $J$ Hepatol. 1995;22(6):696-9. doi: 10.1016/0168-8278(95)80226-6. [PubMed: 7560864].

26. Afdhal N, Zeuzem S, Kwo P, Chojkier M, Gitlin N, Puoti M, et al. Ledipasvir and sofosbuvir for untreated HCV genotype 1 infection. $N$ Engl J Med. 2014;370(20):1889-98. doi: 10.1056/NEJMoa1402454. [PubMed: 24725239].

27. Alqahtani SA, Afdhal N, Zeuzem S, Gordon SC, Mangia A, Kwo P, et al. Safety and tolerability of ledipasvir/sofosbuvir with and without ribavirin in patients with chronic hepatitis $C$ virus genotype 1 infection: Analysis of phase III ION trials. Hepatology. 2015;62(1):25-30. doi: 10.1002/hep.27890. [PubMed: 25963890].

28. Feld JJ, Moreno C, Trinh R, Tam E, Bourgeois S, Horsmans Y, et al. Sustained virologic response of $100 \%$ in HCV genotype $1 \mathrm{~b}$ patients with cirrhosis receiving ombitasvir/paritaprevir/r and dasabuvir for 12 weeks. J Hepatol. 2016;64(2):301-7. doi: 10.1016/j.jhep.2015.10.005. [PubMed: 26476290].

29. Afdhal N, Reddy KR, Nelson DR, Lawitz E, Gordon SC, Schiff E, et al. Ledipasvir and sofosbuvir for previously treated HCV genotype 1 infection. N Engl J Med. 2014;370(16):1483-93. doi: 10.1056/NEJMoa1316366. [PubMed: 24725238].

30. Zoulim F, Liang TJ, Gerbes AL, Aghemo A, Deuffic-Burban S, Dusheiko $\mathrm{G}$, et al. Hepatitis $C$ virus treatment in the real world: Optimising treatment and access to therapies. Gut. 2015;64(11):1824-33. doi: 10.1136/gutjnl-2015-310421. [PubMed: 26449729]. [PubMed Central: PMC5993679].

31. Gondeau C, Pageaux GP, Larrey D. Hepatitis C virus infection: Are there still specific problems with genotype 3? World J Gastroenterol.2015;21(42):12101-13. doi: 10.3748/wjg.v21.i42.12101.[PubMed: 26576095]. [PubMed Central: PMC4641128].

32. American Association for the Study of Liver Diseases; Infectious Diseases Society of America. HCV guidance: Recommendations for test- 
ing, managing, and treating hepatitis $C$. Alexandria and Arlington, VA: AASLD and IDSA; [cited March 15, 2017]. Available from: www. hcvguidelines.org.

33. Kliemann DA, Tovo CV, da Veiga AB, de Mattos AA, Wood C. Polymorphisms and resistance mutations of hepatitis $C$ virus on sequences in the European hepatitis C virus database. World J Gastroenterol. 2016;22(40):8910-7. doi: 10.3748/wjg.v22.i40.8910. [PubMed: 27833382]. [PubMed Central: PMC5083796].

34. Andre-Garnier E, Ribeyrol O, Gournay J, Besse B, Coste-Burel M, Mabille-Archambeaud I, et al. Emergence of HCV resistanceassociated variants in patients failing sofosbuvir-based regimens: An observational cohort. Antivir Ther. 2016;21(7):611-9. doi: 10.3851/IMP3053. [PubMed: 27128103].

35. Sargin Altunok E, Sayan M, Akhan S, Aygen B, Yildiz O, Tekin Koruk $\mathrm{S}$, et al. Protease inhibitors drug resistance mutations in turkish patients with chronic hepatitis C. Int J Infect Dis. 2016;50:1-5. doi: 10.1016/j.ijid.2016.07.003.

36. Sanlidag T, Sayan M, Akcali S, Kasap E, Buran T, Arikan A. [Determination of drug resistance mutations of NS3 inhibitors in chronic hepatitis C patients infected with genotype 1]. Mikrobiyol Bul. 2017;51(2):14555. Turkish. [PubMed: 28566078].
37. Robaeys G, Bielen R, Azar DG, Razavi H, Nevens F. Global genotype distribution of hepatitis $C$ viral infection among people who inject drugs. J Hepatol. 2016;65(6):1094-103. doi: 10.1016/j.jhep.2016.07.042. [PubMed: 27520879].

38. Iyengar S, Tay-Teo K, Vogler S, Beyer P, Wiktor S, de Joncheere K, et al. Prices, costs, and affordability of new medicines for hepatitis $\mathrm{C}$ in 30 countries: An economic analysis. PLoS Med. 2016;13(5). e1002032. doi: 10.1371/journal.pmed.1002032. [PubMed: 27243629]. [PubMed Central: PMC4886962].

39. Loggi E, Gitto S, Galli S, Minichiello M, Conti F, Grandini E, et al. Hepatitis $\mathrm{B}$ virus reactivation among hepatitis $\mathrm{C}$ patients treated with direct-acting antiviral therapies in routine clinical practice. J Clin Virol. 2017;93:66-70. doi: 10.1016/j.jcv.2017.05.021. [PubMed: 28654775].

40. Londono MC, Carrion JA, Forns X. Letter: hepatitis B reactivation in patients with chronic hepatitis $C$ during direct-acting antiviral therapy-authors' reply. Aliment Pharmacol Ther. 2017;45(12):1559-60. doi: 10.1111/apt.14104. [PubMed: 28503869].

41. Honer Zu Siederdissen C, Maasoumy B, Marra F, Deterding K, Port K, Manns MP, et al. Drug-drug interactions with novel all oral interferonfree antiviral agents in a large real-world cohort. Clin Infect Dis. 2016;62(5):561-7. doi: 10.1093/cid/civ973. [PubMed: 26611779]. 
Table 2. Baseline Charectiristics and Demographics of DAAs in Patients with HCV Infection ${ }^{\mathrm{a}}$

\begin{tabular}{|c|c|}
\hline Charectiristic & Study Group \\
\hline Patient & 101 \\
\hline Age, $y$ & $51(22-86)$ \\
\hline Gender & $41(40)$ \\
\hline \multicolumn{2}{|l|}{ HCV genotype } \\
\hline 1a & $28(28)$ \\
\hline $1 \mathrm{~b}$ & $60(59)$ \\
\hline 2 & $2(2)$ \\
\hline 3 & $8(8)$ \\
\hline 4 & $3(3)$ \\
\hline \multicolumn{2}{|l|}{ HCV treatment history } \\
\hline Naïve & $58(57)$ \\
\hline Partial responders & $2(2)$ \\
\hline Null responders & $23(23)$ \\
\hline Relapser & $13(13)$ \\
\hline Discontinuation due to advers reaction & $5(5)$ \\
\hline HCV RNA load, IU/mL & $2.75+\mathrm{E} 6(1.4+\mathrm{E} 3-2.66+\mathrm{E} 8)$ \\
\hline \multicolumn{2}{|l|}{ Fibrosis score } \\
\hline $\mathrm{F} 1$ & $25(37)$ \\
\hline F2 & $14(20)$ \\
\hline F3 & $22(31)$ \\
\hline F4 & $4(6)$ \\
\hline F5 & $4(5)$ \\
\hline F6 & $1(1)$ \\
\hline \multicolumn{2}{|l|}{ Child-Pugh class } \\
\hline A & $8(8)$ \\
\hline B & $1(1)$ \\
\hline $\mathrm{C}$ & ND \\
\hline \multicolumn{2}{|l|}{ Therapeutic regime } \\
\hline LDV/SOF & $29(29)$ \\
\hline $\mathrm{LDV} / \mathrm{SOF}+\mathrm{RBV}$ & $10(10)$ \\
\hline $\mathrm{OBV} / \mathrm{PTV} / \mathrm{r}+/$-DSV & $33(33)$ \\
\hline $\mathrm{OBV} / \mathrm{PTV} / \mathrm{r}+\mid-\mathrm{DSV}+\mathrm{RBV}$ & $19(18)$ \\
\hline $\mathrm{SOF}+\mathrm{RBV}$ & $10(10)$ \\
\hline \multicolumn{2}{|l|}{ Ribavirin use } \\
\hline Yes & $39(39)$ \\
\hline No & $62(61)$ \\
\hline
\end{tabular}


Duration of treatment

\begin{tabular}{|c|c|}
\hline 12 weeks & $86(85)$ \\
\hline 24 weeks & $15(15)$ \\
\hline \multicolumn{2}{|l|}{ Comorbidities } \\
\hline Malignancy (not including HCC) & $2(2)$ \\
\hline Previous IDU ${ }^{\mathrm{b}}$ & $16(16)$ \\
\hline Decompansated cirrhosis & $1(1)$ \\
\hline End stage renal disease & $6(6)$ \\
\hline Diabetes mellitus & $10(10)$ \\
\hline Hypertension & $20(20)$ \\
\hline Depression & $5(5)$ \\
\hline Hypothyroidism & $9(9)$ \\
\hline Thalassemia major & $3(3)$ \\
\hline \multicolumn{2}{|l|}{ Hepatitis B status } \\
\hline HBsAg positive & $2(2)$ \\
\hline Isolated Anti-HBc IgG positive & $8(8)$ \\
\hline HBsAg and Anti-HBs negative & $25(25)$ \\
\hline Anti-HBs and Anti -HBc IgG positive & $66(65)$ \\
\hline \multicolumn{2}{|l|}{ Concomitant drug number } \\
\hline $1-2$ & $17(17)$ \\
\hline $3-4$ & $13(13)$ \\
\hline $5-6$ & $13(13)$ \\
\hline$\geq 6$ & $8(8)$ \\
\hline
\end{tabular}

Abbreviations: F, female, LDV, ledipasvir; ND, not determined; OBV, Ombitasvir; PTV, paritaprevir; r, ritonavir; RBV, ribavirin; SOF, sofosbuvir.

${ }^{\mathrm{a}}$ Values are expressed as No. (\%) or median (rang).

${ }^{\mathrm{b}}$ Previous IDU: Patients who had acquired HCV through previous intravenous drug use (IDU), but who had not injected within the last 6 months and were currently not requiring opioid replacement therapy. 